\title{
Борьба палестинцев за независимость в 1960-1980-е гг.
}

\author{
Гофман А.В. \\ Институт востоковедения Российской академии наук, \\ 107031, Россия, Москва, ул. Рождественка, д. 12 \\ E-mail: gofmanar@yandex.ru
}

\begin{abstract}
Аннотация. Данная статья посвящена становлению палестинского движения за независимость во второй половине XX в. Попытки добиться самостоятельности вооружённым путём привели к росту насилия и жёстким ответным мерам израильской стороны. Постепенно упор был перенесён на дипломатию, позволив палестинцам заручиться международной поддержкой, оказав давление на Израиль. Ради этого палестинцы готовы были признать право Государства Израиль на существование и резолюции ООН как базу мирного урегулирования. Это позволило автору прийти к заключению о гибкости палестинской идеологии сопротивления, высоком уровне прагматичности её лидеров.
\end{abstract}

Ключевые слова: Палестина, Израиль, палестино-израильский конфликт, палестинское движение сопротивления.

Для цитирования: Гофман А.В. 2021. Борьба палестинцев за независимость в 1960-1980-е гг. Via in tempore. История. Политология, 48 (2): 359-366. DOI: 10.52575/2687-0967-2021-48-2-359-366.

\section{Palestinian struggle for independence in 1960-1980}

\author{
Artyom V. Gofman \\ Institute of Oriental Studies Russian Academy of Science, \\ 12 Rozhdestvenka St., Moscow, 107031, Russia \\ E-mail: gofmanar@yandex.ru
}

\begin{abstract}
This article is dedicated to the Palestinian resistance movement for independence in the second half of the XX century. After the First Arab-Israeli War in 1947-1949 many Palestinians were scattered outside their homeland. In 1960's the Palestinian Liberation Organization emerged as a core stone of the independence movement. However, arm resistance led to Israeli crackdown. Perceiving that, Palestinians shifted focus to international sphere where they managed to achieve international support against Israel which positions were damaged. In order to put high pressure on Israelis, Palestinians approved the UN resolutions on the Middle East Peace Process and were ready to recognize Israel. Thus, one can deduce that Palestinian leaders were pragmatic enough to change their positions for the purpose of aspiring to their ends. The same goes with the Palestinian resistance movement ideology. It was changeable enough to fit the current state of affairs. Palestinians failed to beat Israel via arm resistance but they succeed to put enormous pressure on it by means of international support.
\end{abstract}

Keywords: Palestine, Israel, Palestinian-Israeli conflict, Palestinian movement for independence.

For citation: Gofman A.V. 2021. Palestinian struggle for independence in 1960-1980. Via in tempore. History and political science, 48 (2): 359-366 (in Russian). DOI: 10.52575/2687-0967-2021-48-2-359-366.

\section{Введение}

Создание Государства Израиль и последовавшая за этим арабо-израильская война стали настоящей катастрофой для палестинских арабов. Попытки создать свою государственность были прерваны начавшимся конфликтом между Израилем, с одной стороны, и 
соседними арабскими государствами - с другой. И хотя в сентябре 1948 г. при покровительстве Египта было создано Всепалестинское правительство в Газе, иногда называвшееся «палестинским правительством в изгнании», оно не обладало целым рядом факторов, характерных для независимого государства, не было у него и международного признания, кроме стран Лиги арабских государств (ЛАГ) [Эпштейн 2016, с. 237-240].

Исходя из этого, палестинские арабы оказались во многих отношениях самой проигравшей стороной по итогам первой арабо-израильской войны. Этот народ был разделён между соседними странами, многие стали беженцами [Kimmerling, Migdal, 2003, p. 215-216]. Политического единства так и не возникло; более того, палестинский нарратив об освобождении оказался «присвоен» Египтом, задействовавшим его в своих целях, а правительство в Газе существовало в качестве марионетки. На представительство палестинцев также претендовала Иордания, но, в отличие от Египта, иорданцы считали Восточную Палестину неотъемлемой частью Хашимитского королевства, проводя политику «иорданизации» палестинских арабов и отказывая им в праве на самоопределение [Сакер, 2011, c. 425].

В результате «палестинский вопрос стал разменной картой, которую и Израиль, и арабские страны использовали в своих интересах, не привлекая при этом самих палестинских представителей к обсуждению судьбы их народа» [Эпштейн, 2009, с. 35].

В 1950-е гг. палестинский вопрос в какой-то мере потерял свою актуальность для мирового сообщества. Постепенно он сузился до проблемы палестинских беженцев. В условиях нарастания «холодной войны» и отказа ключевых сторон арабо-израильского конфликта вернуться к довоенному положению ситуация в Палестине оставалась в подвешенном состоянии. Ни о создании арабского государства в Палестине, ни об интернационализации Иерусалима речи уже не шло. Стороны конфликта пытались сохранить сложившийся статус-кво.

Создание Организации освобождения Палестины. Одним из первых арабских лидеров, кто заговорил о палестинцах как об отдельной нации, стал лидер Египта Г.А. Насер. На сессии ЛАГ в 1959 г. он заявил о праве палестинцев на самоопределение и собственную территорию [Клява, 2003, с. 164]. В 1963 г. было ликвидировано Всепалестинское правительство, а уже в следующем 1964 г. создана Организация освобождения Палестины (ООП).

Вплоть до 1967 г. ООП не играла особой роли в арабо-израильском конфликте. Вопервых, её деятельность строго контролировалась египетскими властями, которые жёстко пресекали действия боевиков, несогласованные с Каиром. Во-вторых, зона деятельности ООП была ограничена исключительно территорией Израиля без Западного берега, так как это было принципиальным требованием короля Хусейна в качестве поддержки Иорданией ООП.

Стоит сказать, что не все палестинцы были согласны бороться с Израилем под покровительством той или иной арабской страны. В 60-80-е гг. XX в. появлялись, сливались и распадались многие палестинские группировки, действовавшие в рамках ООП или же вне её. Одной из самых влиятельных стала сформировавшаяся на рубеже 50-60 гг. ХХ в. группировка ФАТХ, буквально - «Движение за национальное освобождение Палестины».

До 1967 г. деятельность ФАТХ, не входившей в ООП, была затруднена противодействием ряда арабских стран [Клява, 2003, с. 171-172]. Арабских лидеров раздражала относительная самостоятельность главарей ФАТХ, совершавших зачастую без согласования с ними диверсионно-террористические вылазки в сторону Израиля с территории их государств.

Ситуация кардинально изменилась после победы Израиля в Шестидневной войне 1967 г. Арабские авторы подчёркивают, что проигрыш в войне в определённой степени вынудил арабские режимы открыть путь палестинскому движению сопротивления, приведя к вступлению ФАТХ в ООП, занявшей в последней центральное место, что, в свою очередь, стало мощным стимулом становления «палестинского национального самосозна- 
ния» [Mohsen Moh'd Saleh, 2014, p. 94]. На саммите ЛАГ в Рабате в 1974 г. было подтверждено право палестинцев на самоопределение под руководством ООП как их единственного законного представителя [Lukacs, 1992, p. 464-465]. Фактически ООП стала официальным представителем интересов палестинского народа. Это решение юридически закрепляло основы подхода арабских стран к палестино-израильскому урегулированию, став ключевым фактором дальнейших переговоров.

Возвращение палестинского вопроса в повестку дня международного сообщества. Произошла переоценка палестинского вопроса в международном сообществе. Начало было положено в резолюции 2535 «Ближневосточное агентство Организации Объединённых Наций для помощи палестинским беженцам и организации работ», принятой ГА ООН 10 декабря 1969 г., где, помимо помощи палестинским беженцам, подтверждались «неотъемлемые права народа Палестины» [Resolution 2535]. В резолюции 3236, принятой ГА ООН 22 ноября 1974 г., вновь подтверждались права палестинского народа на самоопределение и национальную независимость [Resolution 3236]. В тот же день была принята резолюция 3237 о наделении ООП статусом наблюдателя в ООН [Resolution 3237]. Таким образом, с середины 1970-х гг. палестинский вопрос снова вернулся в повестку дня $\mathrm{OOH}$, перестав концентрироваться лишь вокруг темы беженцев и дополнившись требованием создания независимого палестинского государства.

Отдельно нужно обратить внимание на базу решения арабо-израильского конфликта. Начиная с 1967 г., её основой становится принцип «территории в обмен на мир». Подразумевалось, что Израиль должен был освободить захваченные территории, а соседние страны - заключить мир с еврейским государством в соответствии с резолюцией 242 СБ ООН, принятой 22 ноября 1967 г. и ставшей краеугольным камнем ближневосточного урегулирования [Resolution 242].

Формально соответствовавшая позиции палестинского движения сопротивления, резолюция 242 призывала к восстановлению довоенных границ и решения проблемы палестинских беженцев. Но в ней ничего не говорилось о праве палестинских арабов на самоопределение. Более того, согласно тексту, непонятно было, что делать с территорией Западного берега и сектора Газа, которые Израиль должен был освободить. В тексте было прописано право каждого государства региона «жить в мире в безопасных и признанных границах» [Resolution 242], но аннексия Иорданией Западного берега не была признана международным сообществом и являлась незаконной, сомнительным было также присутствие египетской военной администрации в Газе.

Интересно отметить, что на следующий день после принятия резолюции ООП опубликовала заявление, по которому организация отказывалась её признавать в том числе и потому, что в ней не прописывалось право палестинского народа на независимость и самоопределение [Lukacs, 1992, p. 290-291].

Вторым спорным моментом было требование вывести израильские войска с оккупированных территорий. В тексте резолюции это было прописано как факт, но не уточнялось - со всех территорий или же частично. А.В. Скосырев обращает внимание на то, что отсутствие чёткого указания освободить все территории стало лазейкой для израильтян, обосновывавших своё право вывести войска только к тем границам, которые они сочтут нужными [Скосырев, 2015, с. 32-33]. Хотя ООП имела поддержку ООН, ЛАГ и ряда других стран, отвергавших израильскую трактовку резолюции, юридические коллизии тем не менее осложняли борьбу за политическую независимость палестинского народа.

Политика ООП в 70-80-е гг. ХХ в. В 1970-е гг. претерпевает изменения политика ООП. К тому моменту пропала надежда на совместное военное выступление ООП и арабских стран против Израиля, особенно после победы израильтян в войне Судного дня 1973 г. [Greenstein, 2014, p. 141]. Ощутимо чувствовался спад популярности панарабизма, 
росли противоречия внутри арабского мира ${ }^{4}$. Объединение всей Палестины под израильским контролем давало ООП пространство для манёвра на оккупированных территориях. Теперь Я. Арафат мог распространять свои идеи среди палестинских арабов, не задевая национальные интересы Аммана ${ }^{5}$ или Каира. Росла зависимость ООП от поддержки Советского Союза, призывавшего Я. Арафата отказаться от диверсионно-террористических методов борьбы.

Советский и российский государственный деятель Е.М. Примаков, находившийся в дружеских отношениях с лидером ООП, писал: «Шестидневная война 1967 года, проигранная арабскими государствами, ещё больше укрепила Арафата в мысли, что завоевание палестинских прав - дело рук самих палестинцев» [Примаков, 2016, с. 237]. На встрече с Е.М. Примаковым летом 1971 г. лидер ООП нарисовал карту, где палестинское государство соседствует с Израилем, а не находится вместо него [Примаков, 2016, с. 243]. Такой поступок противоречил ранее принятым палестинскими представителями документам, где чётко прописывалась необходимость освобождения всей территории Палестины, включая положение о вооружённом сопротивлении сионистским оккупантам [Lukacs, 1992, p. 295-301].

Вполне очевидно, что смещение акцента с насилия на дипломатию уже некоторое время прорабатывалось ещё до встречи. Однако, изучая различные документы палестинского движения сопротивления, можно прийти к выводу, что подобного рода обсуждения долгое время носили кулуарный, неофициальный и, возможно, даже пропагандистский характер ${ }^{6}$. ООП и многие другие палестинские группировки не отказались от насилия как средства достижения политических целей. На протяжении всех 1970-х и 1980-х гг. палестинские боевики совершали многочисленные террористические акции, направленные преимущественно против мирного населения, нонкомбатантов.

Тем не менее процесс развития, адаптации под новые условия, идеологии палестинского движения за независимость действительно имел место. А.Я. Клява выделяет гибкость палестинских идеологов, поясняя, что «идеология палестинского национализма могла "буксовать", идти по кругу, не поднимаясь, и даже долго стоять на месте. Но никогда - не идти назад» [Клява, 2003, с. 36-37]. По мнению Г.Г. Косача, изменение позиции палестинцев было медленным, в том числе и потому, что палестинские арабы рассматривали еврейское государство как временное образование, они не были готовы моментально признать его право на существование или полностью отказаться от его ликвидации [Косач, 2001, c. 143].

Особенно сильны были антиизраильские настроения среди радикалов. ООП никогда не представляла из себя монолитную организацию, а доминирование ФАТХ не означало беспрекословное подчинение ему других формирований. Скорее, это было собрание разных палестинских группировок, объединённых ненавистью к Государству Израиль и желанием освободить Палестину от «сионистского образования». Постоянная угроза раскола ООП, его распада на различные фракции стала самой настоящей хронической проблемой для Я. Арафата.

К началу 1980-х гг. ООП впервые за всю свою историю оказалась на грани распада и исчезновения как серьёзная политическая сила. В результате вторжения израильской армии в Ливан сеть местных палестинских лагерей, на которые опирался Я. Арафат, была разрушена. Лидеру ООП угрожали израильтяне, антипалестинские ливанские силы и сирийцы. В 1983 г. наиболее радикальные представители палестинского движения сопротивления, поддерживаемые Дамаском, выступили против «соглашательской» политики

\footnotetext{
${ }^{4}$ Амбиции Я. Арафата в Иордании привели к событиям «Чёрного сентября» и изгнанию боевиков ООП в Ливан. Там они сталкивались с местными силами, что в итоге привело к началу кровопролитной гражданской войны. Ухудшались отношения ООП с Сирией и Египтом.

${ }^{5}$ На самом деле активность ООП на Западном берегу вызывала раздражение у иорданских властей, считавших, что деятельность Я. Арафата наносит урон связям Иордании со своими бывшими территориями.

${ }^{6}$ Официально ООП признала резолюции ООН и право Израиля на существование только в 1988 г., спустя годы вооружённой борьбы против еврейского государства.
} 
Я. Арафата [Пир-Будагова, 2015, с. 263]. Он смог, однако, преодолеть назревавший раскол, и на сессии Национального совета Палестины в том же году большинство делегатов выразило поддержку «умеренному» курсу Я. Арафата на примирение, включая одобрение Фесского плана ${ }^{7}$, «ястребы» и «голуби» оказались в меньшинстве [Боровой, 2009, с. 92-93].

Перемещение штаб-квартиры ООП в Тунис негативно сказалось на положении палестинского движения сопротивления. Палестинские боевики лишились своей базы в Ливане, с территории которого они могли совершать нападения на Израиль. Ослабли связи с палестинцами на территории Западного берега и сектора Газа. Ухудшились отношения с Иорданией, Сирией. Напряжёнными были отношения с Египтом. Израиль и США попрежнему отказывались вести диалог с ООП. Я. Арафат оказался в изоляции, его возможности влиять на ближневосточное урегулирование были максимально сужены.

Ситуация кардинально изменилась после начала первой интифады в 1987 г. Восстание против израильских властей носило стихийный характер и грозило окончательно переместить фокус внимания с палестинской диаспоры на оккупированные территории [Маначинский, 2014, с. 80]. Особое беспокойство вызывала небывалая прежде активность исламистов из движения ХАМАС, в переводе - «Движение исламского сопротивления» ${ }^{8}$, действовавших без консультаций с Я. Арафатом. В связи с этим ООП вело политику, с одной стороны, необходимости возглавить восстание, что им вскоре удалось, с другой сдерживания политической власти и влияния исламистов.

После отказа Хашимитской династии от претензий на территорию Палестины Я. Арафат начал закулисную игру, чтобы окончательно склонить палестинское движение сопротивления к компромиссному решению палестино-израильского конфликта. И ему это удалось. 15 ноября 1988 г. была опубликована палестинская Декларация независимости, провозглашавшая создание Государства Палестины со столицей в Иерусалиме [Lukacs, 1992, p. 411-415]. Отечественные исследователи отмечают, что эта декларация по стилю и духу очень похожа на Декларацию независимости, зачитанную Д. Бен-Гурионом 14 мая 1948 г. [Боровой, 2009, с. 114-115; Косач, 2001, с. 145-146]. Г.Г. Косач также добавляет, что «Декларация независимости Государства Израиль становилась правовым актом, завершавшим процесс оформления государственности палестинского ишува. В свою очередь, Декларация независимости Государства Палестина, фиксируя существование палестинского национального сообщества, лишь инициировала движение в сторону его самоопределения, когда будущее государство ещё должно было стать естественной формой самостоятельного палестинского бытия» [Косач, 2001, с. 146].

Помимо провозглашения независимости, Я. Арафат также признавал резолюции $\mathrm{OOH}$, посвящённые ближневосточному урегулированию, право Израиля на существование и публично осудил любые проявления терроризма [Lukacs, 1992, p. 420-434]. Его заявления вызвали негативную реакцию радикалов внутри ООП, но дальше осуждений дело не двинулось. В отличие от 1983 г., в 1988 г. Я. Арафат был неоспоримым лидером палестинского движения сопротивления, он имел признание международного сообщества (кроме израильского правительства), включая страны Европы и США.

Как видно, глава ООП нёс значительные политические издержки из-за внутрипалестинского противоборства на протяжении десятилетий. Даже во время мирного процесса

${ }^{7}$ На заседании ЛАГ в Фесе в 1982 г. на основе мирного предложения саудовского короля Фахда арабские лидеры предложили план урегулирования арабо-израильского конфликта, включавший возврат к границам до Шестидневной войны, ликвидацию поселений, решение проблемы беженцев, создание палестинского государства со столицей в Восточном Иерусалиме и т. д. План примечателен тем, что это первое с 1967 г. совместное мирное предложение арабских стран, признававших Государство Израиль. Принимая его, ООП фактически косвенно признала право Израиля на существование уже в 1983 г.

${ }^{8}$ Движение формально было основано шейхом А. Ясином в декабре 1987 г. во время интифады. Имело тесные связи с египетской организацией «Братья-мусульмане», основывалось на радикальном исламизме. 
1990-х гг. он был вынужден постоянно лавировать, изворачиваться, чтобы не допустить раскола в палестинском движении сопротивления. В результате такое поведение использовалось противниками Я. Арафата против него самого, создавая образ «лицемерного» и «лживого» политика, чьи слова практически ничего не значат и не имеют веса.

Активно этот образ продвигали израильтяне. Например, после выступления Я. Арафата на ГА ООН в декабре 1988 г., где он высказал поддержку мирному урегулированию, премьер-министр И. Шамир заявил следующее: «мы стали свидетелями поразительного акта лжи... мираж, иллюзия умеренности была создана для обмана международного сообщества. Тем не менее на всех своих выступлениях... глава ООП повторяет свою основную позицию различными способами. Суть их проста - отказ признать право Израиля на существование, продолжение терроризма и поощрение насилия» [Reaction by Prime Minister Shamir].

\section{Заключение}

Идеология палестинского движения сопротивления прошла длинный и непростой путь. Её становление происходило практически в диаспоре, с активным вмешательством соседних арабских стран, при наличии неудачного опыта самоопределения времён британского мандата. Необходимо было не только избавиться от «удушающей» опеки арабских лидеров, но и пробудить в палестинском народе, разбросанном по всему Ближнему Востоку, рост национального самосознания. Ключевым моментом стало признание за ООП в 1974 г. уникального права предоставлять интересы и вести переговоры от имени палестинцев, что дало козырь в противостоянии с Хашимитским королевством, проводившим политику «иорданизации» арабов Палестины и претендовавшим на территорию Западного берега.

Палестинскому движению сопротивления была свойственна определённая гибкость, адаптация к изменяющейся ситуации. Придерживаясь конечной цели создания независимого палестинского государства, Я. Арафат смог постепенно смещать акценты на его основание рядом, а не вместо Израиля. Но палестинские группировки так и не смогли полностью отказаться от проведения диверсионно-террористических актов даже после 1988 г. Более того, сам Я. Арафат на деле использовал терроризм в качестве рычага давления на Израиль.

Тем не менее формальная готовность ООП к мирному урегулированию поставила Израиль, который отказывался вести с ней диалог, в затруднительное положение. Потребовалось ещё несколько лет, чтобы израильтяне согласились встретиться с палестинцами сначала в составе совместной иордано-палестинской делегации на конференции в Мадриде, а затем уже напрямую с палестинцами в Осло.

\section{Список литературы}

288.

1. Боровой Я.Л. 2009. Человек с тысячью лиц. Ясир Арафат. М., ТЕРРА - Книжный клуб,

2. Клява А.Я. 2003. Палестинское национальное движение: от вооружённой борьбы к «дипломатии с оружием в руках» (1974-1991 гг.) В кн.: Ближний Восток и современность. Сборник статей (выпуск двадцатый). М., Институт изучения Израиля и Ближнего Востока: 35-69.

3. Клява А.Я. 2003а. Формирование организационных структур палестинского национального движения В кн.: Ближний Восток и современность. Сборник статей (выпуск восемнадцатый). М., Институт изучения Израиля и Ближнего Востока: 161-194.

4. Косач Г.Г. 2001. Организация освобождения Палестины: путь к созданию национальной государственности. В кн.: Ближний Восток и современность. Сборник статей (выпуск одиннадцатый). М., Институт изучения Израиля и Ближнего Востока: 142-163.

5. Маначинский А.Я. 2014. Ближний Восток: никогда не прекращающаяся война. Ретроспектива (1982-2006). М., Центр стратегической конъюнктуры, 350.

6. Пир-Будагова Э.П. 2015. История Сирии. ХХ век. М., ИВ РАН, 391. 
7. Примаков Е.М. 2016. Конфиденциально: Ближний Восток на сцене и за кулисами. М., ЗАО Издательство Центр-полиграф, 414.

8. Сакер Г.М. 2011. История Израиля. От зарождения сионизма до наших дней Т. 1: 1807-1951. М., Книжники, Текст, 636.

9. Скосырев А.В. 2015. Стратегия и тактика Израиля в отношении палестинской проблемы на рубеже XX-XXI веков. Дисс. канд. ист. н. 07.00.03. М., 219.

10. Эпштейн А.Д. 2009. Израильтяне и палестинцы: от конфронтации - к переговорам и обратно. М., Мосты культуры, 192.

11. Эпштейн А.Д. 2016. Горизонты и миражи палестинской государственности. М., Институт Ближнего Востока, 430.

12. Greenstein R. 2014. Zionism and its Discontents. A Century of Radical Dissent in Israel/Palestine. London, Pluto Press, 232.

13. Lukacs Y. 1992. The Israeli-Palestinian Conflict: A Documentary Record. Cambridge, Cambridge University Press, 549.

14. Kimmerling B., Migdal J.S. 2003. The Palestinian People. A History. London, Harvard University Press, 568.

15. Mohsen Moh'd Saleh. 2014. The Palestinian Issue. Historical Background and Contemporary Developments. Beirut, Al-Zaytouna Centre For Studies \& Consultations, 224.

16. Reaction by Prime Minister Shamir to Arafat's Speech, 13 December 1988. Israel Ministry of Foreign Affairs. Israel's Foreign Policy. Historical Documents, Vol. 9-10: 1984-1988. Available at: https://mfa.gov.il/MFA/ForeignPolicy/MFADocuments/Yearbook7/Pages/415 \%20Reaction \%20by \%20 Prime \%20Minister \%20Shamir \%20to \%20Arafat-s.aspx (accessed 23 October 2020).

17. Resolution 242. UN Security Council, 1967. Available at: https://www.un.org/securitycouncil/ru/content/resolutions-adopted-security-council-1967 (accessed 25 October 2020).

18. Resolution 2535. United Nations Relief and Works Agency for Palestine Refugees in the Near East. UN General Assembly, $24^{\text {th }}$ session. Available at: https://www.un.org/ru/ga/24/docs/24res.shtml (accessed 24 October 2020).

19. Resolution 3236. Question of Palestine. UN General Assembly, $29^{\text {th }}$ session. Available at: https://www.un.org/ru/ga/29/docs/29res.shtml (accessed 24 October 2020).

20. Resolution 3237. Observer status for the Palestine Liberation Organization // UN General Assembly, $29^{\text {th }}$ session. Available at: https://www.un.org/ru/ga/29/docs/29res.shtml (accessed 25 October 2020).

\section{References}

1. Borovoj Ya.L. 2009. Chelovek s tysyach'yu lic. Yasir Arafat [A person with 1000 faces. Yasir Arafat]. M., TERRA - Knizhnyj klub, 288 (in Russian).

2. Klyava A.Ya. 2003. Palestinskoe nacional'noe dvizhenie: ot vooruzhyonnoj bor'by $\mathrm{k}$ «diplomatii s oruzhiem v rukah» (1974-1991 gg.) [Palestinian national movement: from arm resistance to «diplomacy with a gun in hand» (1974-1991)] V kn.: Blizhnij Vostok i sovremennost'. Sbornik statej (vypusk dvadcatyj). M., Institut izucheniya Izrailya i Blizhnego Vostoka: 35-69 (in Russian).

3. Klyava A.Ya. 2003аю Formirovanie organizacionnyh struktur palestinskogo nacional'nogo dvizheniya [Palestinian national movement leading structure forming] $\mathrm{V}$ kn.: Blizhnij Vostok i sovremennost'. Sbornik statej (vypusk vosemnadcatyj). M., Institut izucheniya Izrailya i Blizhnego Vostoka: 161-194 (in Russian).

4. Kosach G.G. 2001. Organizaciya osvobozhdeniya Palestiny: put' k sozdaniyu nacional'noj gosudarstvennosti [Palestinian Liberation Organization: the way to creation of a national state] V kn.: Blizhnij Vostok i sovremennost'. Sbornik statej (vypusk odinnadcatyj). M., Institut izucheniya Izrailya i Blizhnego Vostoka: 142-163 (in Russian).

5. Manachinskij A.Ya. Blizhnij Vostok: nikogda ne prekrashchayushchayasya vojna. Retrospektiva (1982-2006) [The Middle East: a never-ending war]. M., Centr strategicheskoj kon"yunktury, 350 (in Russian).

6. Pir-Budagova E.P. 2015. Istoriya Sirii. XX vek [Syrian history: the XX century]. M., IV RAN, 391 (in Russian).

7. Primakov E.M. 2016. Konfidencial'no: Blizhnij Vostok na scene i za kulisami [Confidential: the Midle East in front of stage and behind it]. M., ZAO Izdatel'stvo Centr-poligraf, 414 (in Russian). 
8. Saker G.M. 2011. Istoriya Izrailya. Ot zarozhdeniya sionizma do nashih dnej T. 1: 1807-1951 [The history of Israel. From Zionizm origin to modernity. V. 1: 1807-1951]. M., Knizhniki, Tekst, 636 (in Russian).

9. Skosyrev A.V. 2015. Strategiya i taktika Izrailya v otnoshenii palestinskoj problemy na rubezhe XX-XXI vekov [Israeli strategy and tactics towards the Palestinian problem on the brink of XX-XXI centuries]. Diss. kand. ist. n. 07.00.03. M., 219 (in Russian).

10. Epshtejn A.D. 2009. Izrail'tyane i palestincy: ot konfrontacii - k peregovoram i obratno [Israelis and Palestinians: from confrontation to negotiations and vice-versa]. M., Mosty kul'tury, 192 (in Russian).

11. Epshtejn A.D. 2016. Gorizonty i mirazhi palestinskoj gosudarstvennosti [Horizons and mirages of Palestinian statehood]. M., Institut Blizhnego Vostoka, 430 (in Russian).

12. Greenstein R. 2014. Zionism and its Discontents. A Century of Radical Dissent in Israel/Palestine. London, Pluto Press, 232.

13. Lukacs Y. 1992. The Israeli-Palestinian Conflict: A Documentary Record. Cambridge, Cambridge University Press, 549.

14. Kimmerling B., Migdal J.S. 2003. The Palestinian People. A History. London, Harvard University Press, 568.

15. Mohsen Moh'd Saleh. 2014. The Palestinian Issue. Historical Background and Contemporary Developments. Beirut, Al-Zaytouna Centre For Studies \& Consultations, 224.

16. Reaction by Prime Minister Shamir to Arafat's Speech, 13 December 1988. Israel Ministry of Foreign Affairs. Israel's Foreign Policy. Historical Documents, Vol. 9-10: 1984-1988. Available at: https://mfa.gov.il/MFA/ForeignPolicy/MFADocuments/Yearbook7/Pages/415 \%20Reaction \%20by \%20 Prime \%20Minister \%20Shamir \%20to \%20Arafat-s.aspx (accessed 23 October 2020).

17. Resolution 242. UN Security Council, 1967. Available at: https://www.un.org/securitycouncil/ru/content/resolutions-adopted-security-council-1967 (accessed 25 October 2020).

18. Resolution 2535. United Nations Relief and Works Agency for Palestine Refugees in the Near East. UN General Assembly, 24th session. Available at: https://www.un.org/ru/ga/24/docs/24res.shtml (accessed 24 October 2020).

19. Resolution 3236. Question of Palestine. UN General Assembly, 29th session. Available at: https://www.un.org/ru/ga/29/docs/29res.shtml (accessed 24 October 2020).

20. Resolution 3237. Observer status for the Palestine Liberation Organization // UN General Assembly, 29th session. Available at: https://www.un.org/ru/ga/29/docs/29res.shtml (accessed 25 October 2020).

\section{ИНФОРМАЦИЯ ОБ АВТОРЕ}

Гофман Артем Владимирович, лаборантисследователь Отдела изучения Израиля и еврейских общин Института востоковедения РАН, г. Москва, Россия

\section{INFORMATION ABOUT THE AUTHOR}

Artyom V. Gofman, research Laboratory Assistant, Department for the Study of Israel and Jewish Communities, Institute of Oriental Studies, Russian Academy of Sciences, Moscow, Russia 